\title{
Correction to: Future precipitation changes in three key sub-regions of East Asia: the roles of thermodynamics and dynamics
}

\author{
Jiao $\mathrm{Li}^{1,2} \cdot$ Yang Zhao ${ }^{1,3,4} \cdot$ Deliang Chen ${ }^{5}$ (1) Yanzhen Kang ${ }^{6} \cdot$ Hui Wang ${ }^{1}$
}

Published online: 13 February 2022

(c) The Author(s) 2022

\section{Correction to: Climate Dynamics \\ https://doi.org/10.1007/s00382-021-06043-w}

In the original publication of the article, there is a typesetting error in the order of reference list about Li et al. (2019a) and Li et al. (2019b).

Li et al. (2019a) should be as.

Li Z, Sun Y, Li T, Ding Y, Hu T (2019a) Future changes in East Asian summer monsoon circulation and precipitation under 1.5 to $5{ }^{\circ} \mathrm{C}$ of warming. Earth's Future 7:1391-1406. https://doi.org/10.1029/2019EF001276.

Li et al. (2019b) should be as.

Li J, Ding R, Wu Z, Zhong QJ, Li BS, Li JP (2019b) Interdecadal change in potential predictability of the East Asian summer monsoon. Theoret Appl Climatol 136:403-415. https://doi.org/10.1007/s00704-018-2482-9.

Correspondingly, there is correction about the reference citation $\mathrm{Li}$ et al. (2019a) in the original publication of the

The original article can be found online at https://doi.org/10.1007/ s00382-021-06043-w.

Yang Zhao

zy5000609@snu.ac.kr

$\triangle$ Deliang Chen

deliang@gvc.gu.se

1 State Key Laboratory of Severe Weather, Chinese Academy of Meteorological Sciences, Beijing, China

2 Institute of Atmospheric Sciences, Fudan University, Shanghai, China

3 Research Institute of Basic Sciences, Seoul National University, Seoul, Republic of Korea

4 School of Earth and Environmental Sciences, Seoul National University, Seoul, Republic of Korea

5 Regional Climate Group, Department of Earth Sciences, University of Gothenburg, Gothenburg, Sweden

6 College of Meteorology and Oceanography, National University of Defense Technology, Changsha, China article in the introduction section. The new text could read as,

"Similarly, Li et al. (2019a) found that both the overall EASM circulation and precipitation will be enhanced under global warming, which is different from the projection for other monsoon regions. Moreover, the relative contributions from the dynamic and thermodynamic components to future precipitation changes are similar when the global warming increase is less than $2{ }^{\circ} \mathrm{C}$, but the dynamic component becomes dominant under further warming. Ha et al. (2020) examined projections in the Phase 6 of the ensemble experiments of the Coupled Model Intercomparison Project (CMIP6), and diagnosed an earlier onset and later termination of the projected EASM, but their study did not identify the underlying causes of the changes."

This error does not affect the previously published results. The original article has been corrected.

Publisher's Note Springer Nature remains neutral with regard to jurisdictional claims in published maps and institutional affiliations. 